\title{
Micro-inclusions in monocrystalline octahedral diamonds from Diavik, Slave Craton: Clues to diamond genesis
}

\author{
D.P. Araújo, W.L. Griffin, S.Y. O'Reilly \\ GEMOC, Dept. Earth \& Planetary Sciences, Macquarie Univ., NSW 2109, Australia
}

Some gem-quality octahedral diamonds from Diavik Mine, Slave Craton, have abundant shallow planar trigons over part or all their surfaces or above macle and fracture lines (Fig.1). Microscope observation of the etched surfaces revealed the occurrence of micro-inclusions $\left(<\begin{array}{ccc}< & 0.5 & \mu \mathrm{m}\end{array}\right)$ concentrated in layers $\sim 10-15 \mu \mathrm{m}$ beneath the surface. Areas with higher concentration of micro-inclusions are separated by curvilinear boundaries from smaller areas where they are absent. The micro-inclusions are rounded with small single fractures extending from them, producing a tadpole-like shape. The microfractures can be both crystallographically (111) and randomly oriented (Fig.1). Shadows of trigons can be seen under non-etched surfaces, suggesting that diamond growth on those faces continued after etching. Micro-inclusions are also seen along fractures and macle lines associated with trigons.

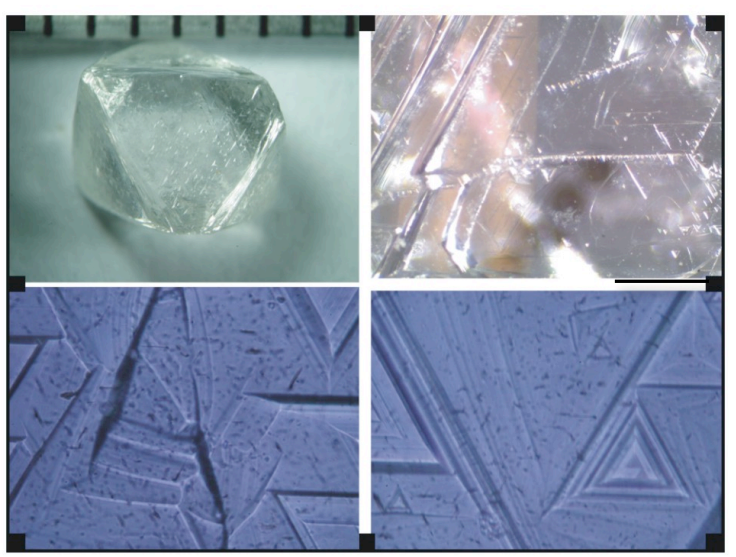

Fig.1 Sharp octahedral diamond from Diavik with abundant trigons (top left). Trigons aligned over fractures (top right, bar is $1 \mathrm{~mm}$ ) and microscopic view of micro-inclusions (40x objective; focused on micro-inclusions).
Four diamonds measured by FTIR are Ia to IaAB (up to $20 \%$ of B centers) with 220 to $770 \mathrm{ppm}$ Nitrogen. Time-resolved LA-ICP-MS analyses (100 $\mu \mathrm{m}$ spot size) were done on etched and non-etched surfaces. In one diamond (DVK109), ablation of the etched surfaces shows an increase in trace-element contents coinciding with the sub-surface inclusion-rich layers. The time-resolved signals for several analyses across single surfaces show that the thickness of the micro-inclusion layers is variable and does not exceed $40 \mu \mathrm{m}$. In Fig. 2, the change in counts/s for Ba during an analysis (130 seconds, to ca $65 \mu \mathrm{m}$ depth) shows the layer of micro-inclusions between $\sim 10$ to $40 \mu \mathrm{m}$ depth. Absolute concentrations change according to the analysis location, reflecting the abundance of microinclusions. Analyses of non-etched surfaces do not show such trace element-enriched layers.

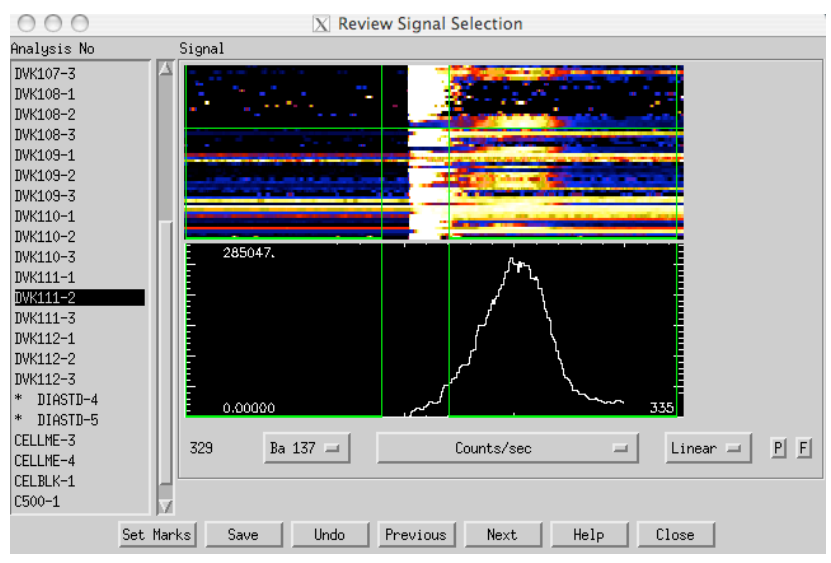

Fig. 2 - Time-resolved linear signal for Ba (counts/s) during ablation (130 seconds, $\sim 65 \mu \mathrm{m}$ deep; GLITTER software Window).

The micro-inclusions have high $\mathrm{Ba}, \mathrm{K}$, LREE (Table 1), $\mathrm{Ba} / \mathrm{La}_{(\mathrm{CN})}$ and $\mathrm{Ba} / \mathrm{Lu}_{(\mathrm{CN})}>>1$ and a positive $\mathrm{Sr}_{(\mathrm{CN})}$ anomaly relative to $\mathrm{Sm}$ compared to the composition of diamond beneath non-etched surfaces. The chondrite-normalised trace-element patterns of the micro-inclusions are comparable to the coats of coated diamonds from the same kimberlite (Griffin et al. this conference, Abst-102). The trace-element levels are intermediate between the levels seen in the diamond coats and the diamond beneath the non-etched surfaces 
for elements such as LREE, $\mathrm{Ba}, \mathrm{Th}, \mathrm{Nb}$ and $\mathrm{Sr}$, but are similar to the non-etched surfaces for HREE and most HFSE. Although the absolute trace element contents of the microinclusion-rich layers are lower than the coats, the $\mathrm{CN}$ pattern is similar, reflecting the lower abundance of micro-inclusions.

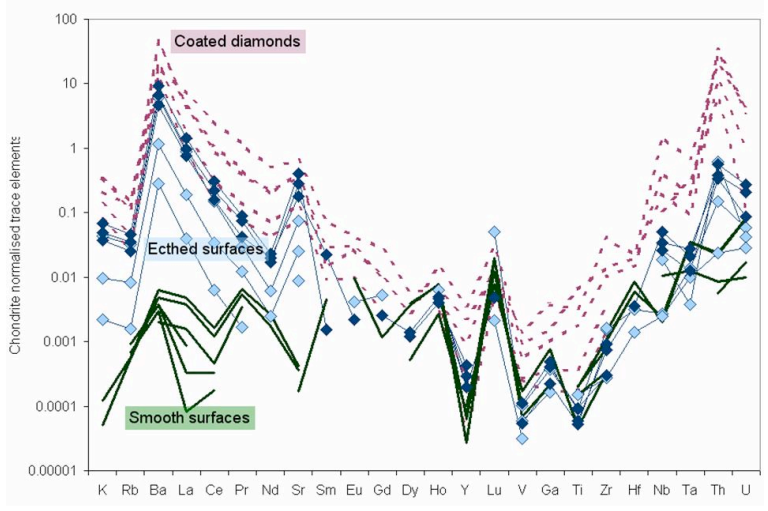

Fig.3 - Chondrite-normalised trace element patterns of etched (rhombic) and non-etched surfaces (solid lines) of octahedral diamonds (this work) and of coated diamonds (dashed lines; Griffin et al. Abst-102).

Table 1 - Range of composition (ppm) and 1 sigma error (average) of layers of micro-inclusions in diamonds DVK109 and DVK111 (6 analyses).

\begin{tabular}{|c|c|c|c|}
\hline & Min & Max & $1 \sigma($ ave $)$ \\
\hline $\mathrm{K}$ & 1.9 & 58 & 1.8 \\
\hline $\mathrm{Rb}$ & 0.006 & 0.2 & 0.004 \\
\hline $\mathrm{Ba}$ & 1.0 & 32 & 0.7 \\
\hline $\mathrm{La}$ & 0.01 & 0.5 & 0.004 \\
\hline $\mathrm{Ce}$ & 0.006 & 0.30 & 0.002 \\
\hline $\mathrm{Pr}$ & 0.0002 & 0.012 & 0.0002 \\
\hline $\mathrm{Nd}$ & $<0.00104$ & 0.017 & 0.001 \\
\hline $\mathrm{Sr}$ & 0.1 & 4.9 & 0.03 \\
\hline $\mathrm{Sm}$ & $<0.00056$ & 0.005 & 0.0005 \\
\hline $\mathrm{Eu}$ & $<0.00016$ & 0.0004 & 0.0001 \\
\hline $\mathrm{Gd}$ & $<0.00069$ & 0.002 & 0.0004 \\
\hline $\mathrm{Dy}$ & $<0.00035$ & 0.0005 & 0.0003 \\
\hline $\mathrm{Ho}$ & $<0.00009$ & 0.0005 & 0.0001 \\
\hline $\mathrm{Y}$ & $<0.00019$ & 0.0010 & 0.0002 \\
\hline $\mathrm{Lu}$ & $<0.00006$ & 0.0019 & 0.0001 \\
\hline $\mathrm{V}$ & $<0.0020$ & 0.010 & 0.001 \\
\hline $\mathrm{Ga}$ & $<0.0022$ & 0.007 & 0.001 \\
\hline $\mathrm{Ti}$ & $<0.0112$ & 0.10 & 0.01 \\
\hline $\mathrm{Zr}$ & 0.002 & 0.01 & 0.0006 \\
\hline $\mathrm{Hf}$ & $<0.00023$ & 0.0006 & 0.0002 \\
\hline $\mathrm{Nb}$ & 0.0009 & 0.02 & 0.0005 \\
\hline $\mathrm{Ta}$ & 0.0001 & 0.0007 & 0.0002 \\
\hline $\mathrm{Th}$ & 0.00101 & 0.03 & 0.0004 \\
\hline $\mathrm{U}$ & 0.0004 & 0.003 & 0.0001 \\
\hline & & & \\
\hline
\end{tabular}

The oxidation of diamond surfaces to produce etching features can take place in the mantle, during diamond growth, or during ascent in the kimberlite magma. Trigons are formed on primary octahedral surfaces and are related to defects, microcracks and impurity clusters, which will determine their morphology and distribution in the diamond surface. Point-bottomed trigons originate at the emergence points of dislocation lines, which commonly occur as bunches emerging from the center of the diamond mostly towards the central portion of the faces, as revealed by X-ray diffraction (Frank and Lang 1965, Khokhryakov and Palynov 2006). As a result pointbottomed trigons related to outcropping bunches are much less abundant near the edge of the surfaces. Flatbottomed trigons, on the other hand, are related to microcracks and impurity clusters. Etching experiments on diamond plates imaged by X-ray diffraction (Khokhryakov and Palynov 2006) showed that point-bottomed trigons, related to dislocation lines, persisted after repeated etching and flat-bottomed trigons eventually disappeared. We suggest that the formation of abundant flat-bottomed trigons on the Diavik diamonds is related to defects due to the occurrence of the sub-surface layer of microinclusions. Coated diamonds from Diavik have similar etching patterns, although trigons are even more abundant.

SHRIMP ${ }^{13} \mathrm{C} /{ }^{12} \mathrm{C}$ in-situ analyses (in prep.) on a diamond plate (DVK109) show around 3 per mil difference between the micro-inclusion layers at the rims (lower ${ }^{13} \mathrm{C} /{ }^{12} \mathrm{C}$ ) and a point $100 \mu \mathrm{m}$ further towards the center.

High growth rate contributes to fibrous growth and incorporation of impurities. During diamond growth these high rates reflects increasing carbon supersaturation of the system, which can be achieved by lowering the temperature and/or by increasing the chemical potential difference between solid and solvent phases (Sunagawa 1984). The presence of a diamond seed for diamond growth may also play a role in the mechanism of growth, as seen in diamond synthesis. Arima et al. (2002) reported nucleation and growth of diamonds in the carbonatitic system $\mathrm{CaMg}\left(\mathrm{CO}_{3}\right)_{2}-\mathrm{Si}$ $\left(7.7 \mathrm{GPa} ; 1500-1800^{\circ} \mathrm{C}\right)$ and observed nucleation of octahedral diamonds and also fibrous diamonds grown over seeds. In the absence of $\mathrm{Si}$, no nucleation was produced. The first diamonds formed at starting composition $0.79 \mathrm{CaMg}\left(\mathrm{CO}_{3}\right)_{2}+0.21 \mathrm{Si}$.

The fluids forming coated diamonds from Diavik are related to carbonatitic/kimberlitic melts (Griffin et al. Abst-102). The chemical resemblance of the "tadpole" micro-inclusions to the fluids trapped in Diavik diamond coats, and the distribution of microinclusions in layers suggest that such fluids also have been present during the growth of monocrystalline diamonds. Changes in growth mechanism due to temperature and/or oxygen fugacity variation can influence the incorporation of micro-inclusions through rapid growth (Sunagawa 1984). However, the distinct trace-element patterns and ${ }^{13} \mathrm{C} /{ }^{12} \mathrm{C}$ ratios of the microinclusion layers suggest that the layers reflect the 
influx of new fluids into the growth environment. The distinctly different trace-element pattern of the diamond in the center and outermost rim of the four diamonds studied here suggests that these parts of the diamond grew from a fluid quite different from the one trapped in the microinclusions, and in the coats on coated diamonds. The occurrence of the microinclusions as layers within these diamonds suggests that these two different types of fluid coexisted within the local metasomatic environment in which the octahedral diamonds grew.

\section{References}

Griffin, W.L., Araujo, D.P., O'Reilly, S.Y., Rege, S., van Achterbergh, E., 2008. Diamonds and carbonatites in the deep lithosphere: Evidence of genetic links. $9^{\text {th }}$ International Kimberlite Conference, Extended Abstracts 102.

Sunagawa, I., 1984. Morphology of natural and synthetic diamond crystals. In: Sunagawa I (ed) Material Science of the Earth's Interior, vol. Terra Scientific Publishing Company (TERRAPUB), Tokyo, pp 303330

Khokhryakov, A.F., Palyanov, Y.N., 2006. Revealing of dislocations in diamond crystals by the selective etching method. Journal of Crystal Growth 293, 469474. 